\title{
Hauchumsprung and the historical phonology of Greek *h
}

\author{
Ollie Sayeed \\ University of Pennsylvania \\ sayeedo@sas.upenn.edu
}

\begin{abstract}
Ancient Greek underwent a sporadic sound change that copied an * $h$ from the second syllable of a word to the first syllable, applying when the first syllable was vowel-initial, and perhaps also when it was stop-initial; this complements the analyses proposed so far in Greek historical phonology, particularly Sturm (2016, 2017), in accounting for the various sources of Proto-Greek * $h$. This change, Hauchumsprung, is unusual among recorded sound changes for involving the copying of a consonant over intervening

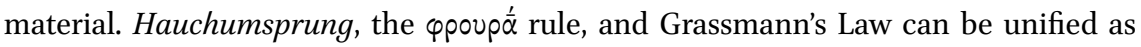
three different footprints of a single sound change: one that copied aspiration from the middle of a word to the beginning of a word in early Greek.
\end{abstract}

\section{Keywords}

Greek - aspiration - Grassmann - Hauchumsprung - historical - phonology

Higgins: "In Hertford, Hereford, and Hampshire, hurricanes hardly ever happen."

Eliza: "In 'Ertford, 'Ereford and 'Ampshire, 'urricanes 'ardly hever 'appen." Higgins: "Oh, no, no! Have you no ear at all?"

My Fair Lady 
This paper is about the ancient Greek sound change informally called Hauchumsprung (Lejeune 1972):

If a word began with a vowel or * $\mathrm{w}$ and exhibited an *h between the first and second syllabics, either intervocalic or as part of a cluster including a sonorant, the *h was copied into the onset of the initial syllable.

RINGE, forthc.

As we'll see, a survey of the Greek lexicon shows that something like Hauchumsprung (or $H$-sprung for short) is active in at least Attic Greek, and sometimes other dialects - but the change seems to be sporadic and rare. Section 1 summarizes what's already known about the origins of * $h$ in other environments in Greek; section 2 presents some positive examples of $H$-sprung, along with a connected change that I call the $\varphi p o u p \frac{\dot{\alpha}}{\text { rule; }}$ and section 3 presents the exceptions to $H$-sprung. Section 4 proposes that $H$-sprung and the $\varphi$ poupó rule, along with a hypothesized precursor to Grassmann's Law, are part of a more general sound change-'Urhauchumsprung' - copying aspiration from the middle of a word to the beginning.

\section{Ancient Greek $h$}

The historical phonology of $h$ in Greek is mostly well-understood. There are four regular sources of early Greek $h$ :

1. ${ }^{*} s$ in most positions

2. ${ }^{*} H i$ word-initially

3. insertion before word-initial * $u$

4. * $u$ word-initially, under particular conditions

Like Iranian and Armenian, Greek has debuccalization of PIE *s to $h$ in most positions. Word-initially, ${ }^{*} s>h$ is conventionally spelt in the ancient Greek alphabet using the 'rough breathing' sign 'over a following vowel, as in *septín 'seven' > $\dot{\pi} \tau \dot{\alpha}$; the 'smooth breathing' ' spells a word-initial vowel without an $h$ before it. In psilotic dialects of Greek (from $\psi\left(\lambda \lambda^{\prime} \varsigma\right.$ 'smooth'), we see a regular loss of initial $h$. Intervocalically, ${ }^{*} h$ disappears in all dialects except Mycenaean,

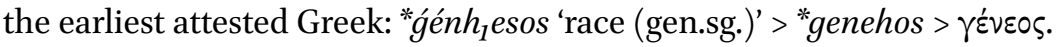

Next to stops and word-finally, ${ }^{*} s$ stays as a sibilant: ${ }^{*} h_{1} e ́ s t i$ 'he/she/it is' >

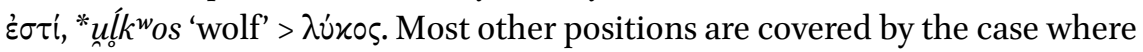
* $s$ is next to a resonant, either initially or medially, in which case it becomes ${ }^{*} h$. Initially, ${ }^{*} h R>{ }^{*} R>R$, with mostly the same outcome as an initial resonant. Medially, ${ }^{*} h R$ and ${ }^{*} R h$ have a complicated range of outcomes; the most 
common in Attic-Ionic and in the West Greek dialects is a singleton $R$ with compensatory lengthening of the preceding vowel, and in Thessalian and Lesbian, a geminate $R R$ with no lengthening of the vowel.

The second source of ${ }^{*} h$ is word-initial ${ }^{*} H i$, where ${ }^{*} H$ is any of the three PIE laryngeals: *Hiék ${ }^{w}{ }_{r}$ 'liver' > $\hat{\eta} \pi \alpha \rho$. A third source is word-initial * $u$, as in $\tilde{u} \delta \rho \alpha$ 'sea serpent' < * $u d r e ́ h_{2}$ : so words in non-psilotic dialects aren't allowed to begin

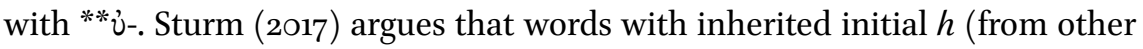
sources) before $u$ came to be more common than words beginning with plain $u$, so speakers analogized $h$ to all originally $u$-initial words.

The final source is word-initial ${ }^{*} u$, under a set of conditions that Sturm (2016) analyses as the presence of a following turbulent segment. In i $\sigma \tau \omega \rho$ 'one who knows' < *uistōr < *uid-tōr, we see $h$ (giving this rule its traditional name of the ' $(\sigma \tau \omega \rho$ rule'); but हैंนธ 'year' < *uetos is vowel-initial. Accepting Sturm's rule means we don't need Ringe's addendum about $H$-sprung also affecting initial ${ }^{*} u$ : we can treat any * $u$-initial words giving us later $h$ as instances of the $i \sigma \tau \omega \rho$ rule, not $H$-sprung.

\section{H-sprung}

\subsection{Examples of $\mathrm{H}$-sprung}

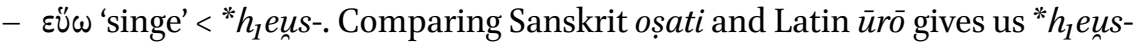

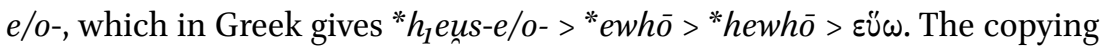
of the $* h$ from the onset of the second syllable to the beginning of the word is an example of $H$-sprung.

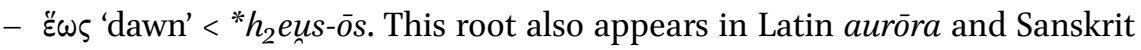
uṣás- (in the zero-grade). We apparently have * $h_{2}$ euss-ōs $>$ *awhōs $>$ *hawhōs

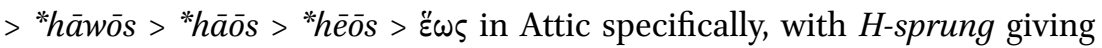
an initial $h$. Ionic has $\eta \dot{\omega} \varsigma$ without the Attic shortening of * $\bar{e}$ before another vowel, and Argolic has epigraphic $\dot{\varepsilon} \pi^{\prime} \dot{\alpha} f \hat{\omega}$ preserving the original * $w$; based at least on the Attic form, we have no initial $h$ and no $H$-sprung. The isolated derivative îpı 'early' $<* \bar{a} r i<*$ awheri $<{ }^{*} h_{2}$ euss-er- $i$ also doesn't show H-sprung.

- $\hat{\eta} \mu \alpha \mathrm{l}$ 'sit' < ${ }^{*} h_{1} e h_{1} s$-. From ${ }^{*} h_{1} e h_{1} s$ - attached to a 1sg. *-mai, we apparently have *ēsmai > *ēhmai > *hēhmai > Homeric $\hat{\eta} \mu \alpha \mathrm{l}$, with the initial $h$ by $H$ sprung seen in derivatives like $\alpha \varphi \eta \mu \alpha$, है $\varphi \eta \mu \alpha \iota, \chi \alpha \dot{\theta} \eta \mu \alpha$ l. We see $h$ throughout the paradigm, including in 3 sg. $\hat{\eta} \sigma \tau \alpha$ เ with no historical * $h$ cluster, so Ringe (forthc.) proposes analogy with the $H$-sprung forms.

- $\dot{\eta} \mu \varepsilon \hat{\imath}$ 'we' < *ns-me. From PIE *ns-me, seen in Avestan ahma and Sanskrit

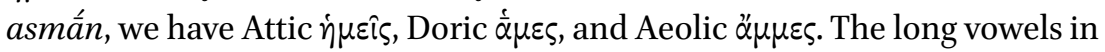


Attic and Doric, and the geminate in Aeolic, are outcomes of the * $h m$ cluster; the $h$ in Attic and Doric must be from $H$-sprung. Sihler (1995) proposes

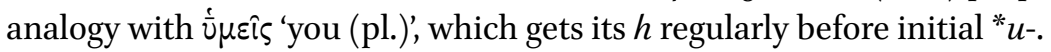

- ivía 'reins' < " $h_{2}$ ens-. Beekes and van Beek ('BvB'; 2010) compare Latin ānsa 'handle' and Irish éisi (pl.) 'reins' to reconstruct ${ }^{*} h_{2}$ ens-, which has to give us Greek ${ }^{*} h_{2}$ ens-iai > *ansiai > *anhiai > *hanhiai > "hāniai > jंvía. Unexpectedly, the root appears without aspiration in Laconian $\alpha \dot{v}$ ıox $\chi^{\prime} \bar{v} v$ (Colvin 2006).

- oînos 'way, course' < ${ }^{*} h_{1} o$ i-s-mo-. Alongside vowel-initial oînos, we have a form oifoos with initial $h$, as well as a compound $\varphi$ poípıov (see below) showing aspiration; the root is * $h_{1} e e_{n}$ - 'go' in the $o$-grade.

Following Ruijgh (1967:61), Ringe (forthc.) suggests that $H$-sprung could also be used to explain $\alpha$ p $\mu \alpha$ 'chariot' $<{ }^{*} h_{2} e r$-smn, from a root ${ }^{*} h_{2} e r$ - 'fit' also seen in ápapi $\sigma x \omega$. Brugmann (1907) explains övos 'ass' as cognate with Latin asinus, supposedly both borrowings from the same language, through an earlier *osonos $>$ *ohonos > *hoonos misparsed as ó ovos 'the ass'; but this is very speculative.

Finally, as a productive grammatical residue of $H$-sprung, the language regularly adds $h$ to the beginning of augmented forms of $h$-initial verbs (Lejeune

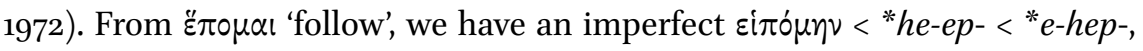
with transfer of * $h$ to the augment by $H$-sprung.

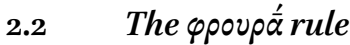

There are a few attested forms (Sihler 1995:173,) that apparently show a medial * $h$ aspirating an initial stop, all from compounds of $\pi \rho 0-: \varphi p o u p \frac{1}{\alpha}$ 'watch' $<$ *pro-

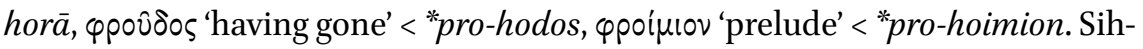
ler proposes that $\pi \rho 0-\sim \varphi \rho O$ - is a new alternation in some idiolects by analogy with lautgesetzlich alternations like $\dot{\varepsilon} \pi-\sim \dot{\varepsilon} \varphi$-; but this would require a strange analysis by the learner in which $\dot{\varepsilon} \pi$ - and $\dot{\varepsilon} \varphi$ - are separate allomorphs conditioned by the phonology of the root, rather than straightforward outcomes of a regular process turning $/ \mathrm{p}+\mathrm{h} /$ into $/ \mathrm{p}^{\mathrm{h}} /$. Instead, we could notice that the чpoupó rule has the same effect as $H$-sprung, except in an complementary set of environments. We could collapse the two by widening the definition of $\mathrm{H}$ sprung to include voiceless stops as targets-simplifying the statement of the change, meaning ${ }^{*} h$ now aspirates everything that can be aspirated.

The form ypoímov is interesting and potentially awkward, because if the

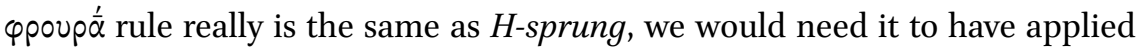
twice in the history of the same form: ${ }^{*} h_{1}$ oismion $>$ *oihmion $>$ *hoimion by $H$-sprung, then "pro-hoimion > $\varphi$ poíplov, also by $H$-sprung. But we can give ourselves a possible solution in terms of relative chronology. If pro- was affixed to a form *oihmion, and then vowel contraction happened before $H$-sprung, we would get *proihmion > $\varphi$ poíplov with only one round of $H$-sprung. This means 
Qpoímov and oifos got their aspiration in parallel, by both being input to $\mathrm{H}$ sprung, not because the former is derived from the latter.

There are a few more words with no evidence of aspiration, even though they contain an initial voiceless stop followed by ${ }^{*} h$ in the next syllable: $\pi \varepsilon \varepsilon^{\prime} \varsigma$

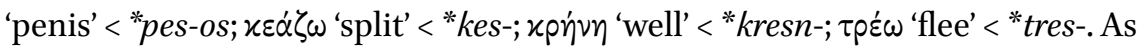
Jay Jasanoff (p.c.) points out, we can take this as evidence that the $\varphi$ poup $\bar{\alpha}$ rule applied after the loss of intervocalic ${ }^{*} h$. This means the three $\varphi$ poupá forms are all later formations, which fits with their productive status as compounds; so the ${ }^{*} h$ in * pro-hora etc. must have survived thanks to being in initial position.

\section{Exceptions to $H$-sprung}

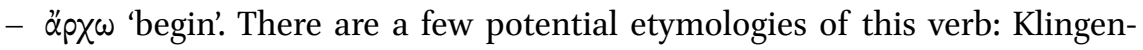
schmitt (1974) proposes ${ }^{*} h_{2} r$-ske/o- from some root ${ }^{*} h_{2} e r$-, while LIV ${ }^{2}$ proposes $*\left(h_{2}\right) r g^{h_{-}}$ske/o- from a root ${ }^{*} h_{2} \mathrm{erg}^{h_{-}}$, also found in modern German ragen 'rise'. In most * $C s C$ sequences in Greek (including this one), " $s$ was lost, so this word might not be expected to show $H$-sprung anyway.

- aúpiov 'tomorrow' < * $h_{2}$ euss-r- 'dawn'. BvB (2010) compare Lithuanian aušrà 'dawn' and Sanskrit usrá- 'morning', both derivatives of * $h_{2}$ eus- 'dawn'. Unlike

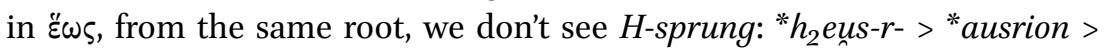
aüpiov (**aüpiov).

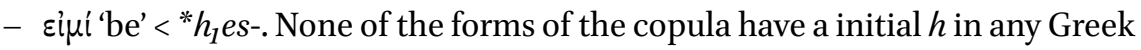

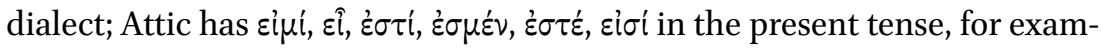
ple. In $\varepsilon i \mu \hat{i}<*{ }^{*} e h m i, \varepsilon \hat{i}<{ }^{*} e h i$, and $\varepsilon i \sigma i<*$ *ehenti, we'd expect $H$-sprung to apply. Ringe (forthc.) suggests levelling from vowel-initial $\dot{\varepsilon} \sigma \tau i$ and $\dot{\varepsilon} \sigma \tau \dot{\varepsilon}$, which keep ${ }^{*} s$ before a stop, as has already happened in $\dot{\varepsilon} \sigma \mu^{\prime} v$ (expected ** $\left.{ }^{*} i \mu \varepsilon v\right)$ ); but speakers would have to level the lack of * $h$ without levelling the full stem, or

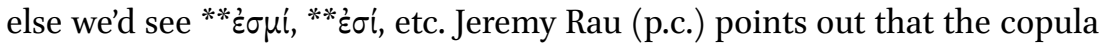
was enclitic on the previous word, in which case the beginning of the root might not count as 'word-initial' for the purposes of $H$-sprung.

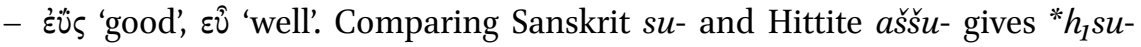
'good' (BvB 2010), which should give **ev- under H-sprung. The use of this

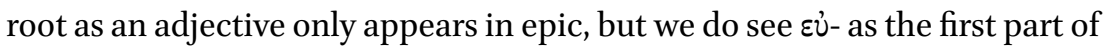
a compound in Attic.

- óppos 'rump', oủ pó 'tail'. BvB (2010) compare a cognate set including modern English arse and Old Irish err 'tail' to reconstruct a root ${ }^{*} h_{1}$ ers- $h_{2}-$. In the $o$ grade, this gives us a doublet ${ }^{*} h_{1}$ ors- $h_{2}>{ }^{*}$ orsa $>1$ ) oujpd́, with $\langle 0 v\rangle$ spelling the output of compensatory lengthening, and 2 ) óppos, with assimilation ${ }^{*} r s$ $>$ pp. We don't see **óppos or **oúpá by $H$-sprung. 
- oûऽ 'ear', oblique stem $\dot{\omega} \tau$-. The PIE paradigm of this word has nominative and accusative ${ }^{*} h_{2} \hat{o}$ ó s, genitive ${ }^{*} h_{2}$ éusos. The oblique cases should show $\mathrm{H}$ sprung from an innovated ${ }^{*} h_{2}$ ous-nt- $>{ }^{*}$ ousat $>{ }^{*}$ ouhat- $>\omega \dot{\tau} \tau-(\mathrm{BvB} 2010)$. Ringe (forthc.) suggests that the lack of initial $h$ is by analogy with oै $\psi$ 'eye', which could also be the source of the $o$-grade vowel in the oblique cases; another possibility, pointed out by an anonymous reviewer, is levelling from nominative-accusative * $h_{2}$ ó $u s$.

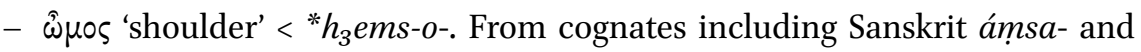
Latin umerus, we can reconstruct ${ }^{*} h_{3}$ ems-o-; the long vowel in Greek could be an inherited lengthened-grade or an irregular outcome of the first compensatory lengthening, but we don't have an aspirated ${ }^{* *} \AA \mu \circ$. $^{\circ}$

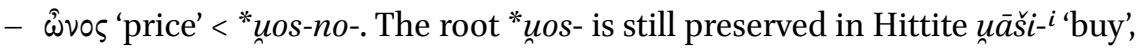
and the *no- derivative appears in Sanskrit vasná- 'price' and Latin vēnum 'object for sale'; Greek shows $\grave{\omega} v \circ \varsigma$ rather than ** ${ }^{*} v o \varsigma$. Along with $\hat{\omega} \mu \circ \varsigma$, this form is independently odd for having the wrong outcome of the first compensatory lengthening.

Ringe's condition that $H$-sprung is blocked by an $o$ vowel is based on oujpó,

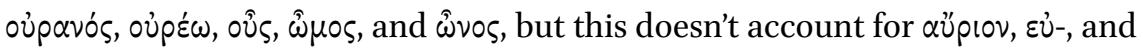
perhaps $\ddot{\alpha} p \chi \omega$ and $\varepsilon i \mu i$ (if these are real counterexamples). Based on these etymologies, it seems that $H$-sprung wasn't a regular sound change in Greek.

\section{4}

\section{Discussion}

Except for $\dot{\eta} \mu \varepsilon \hat{\imath} \varsigma$, none of the apparent positive examples of $H$-sprung seem explainable either by analogy with other forms or by re-evaluating the relevant etymologies; there are no forms of these paradigms that regularly show initial $h$, and the cognates from elsewhere in IE are clear enough that the words couldn't have begun with * $H i$ or * $u$. If this is right, then although $H$-sprung wasn't a regular sound change, we have to accept it at least as a sporadic change to this set of words.

As far as I know, $H$-sprung is unusual and possibly unique among recorded sound changes for copying a consonant over intervening material. There are attested sound changes that copy vowels over intervening consonants, as in the change in Hoocąk (Siouan) that breaks up consonant clusters by inserting a copy of the following vowel (Rankin et al. 2006), or perhaps Avestan $i$-epenthesis (Martínez and de Vaan 2014). There are attested sound changes that move consonants over intervening syllables, as in the long-distance displacement of liquids in the Occitan dialect of Bagnères-de-Luchon (Grammont 1905). And there are synchronic rules that can copy a consonant over inter- 
vening vowels, as in the morphological reduplication processes well known from Indo-European, or the Amharic-based secret language used by sex workers in Addis Ababa that doubles all word-final consonants across an epenthetic schwa (McCarthy 1984). But none of these are quite parallel to $H$-sprung: a sound change (not a synchronic rule) that copies (not moves) consonants (not vowels).

The closest process I know of is the quite rare copying of $/ \mathrm{r} /$ across syllables in some varieties of American English (Hall et al. 2017), as in farmiliar for familiar, or phortographer for photographer. If $H$-sprung really is a sporadic sound change, this sporadic AmE $r$-copying would be a good parallel.

\section{1}

Motor planning?

One intuitively possible explanation for $\mathrm{H}$-sprung is in terms of motor planning. Rather than just surface assimilation caused by anticipating the spread glottis gesture one syllable too early, $H$-sprung could have originated as a speech error. In the UCLA database of speech errors described in Fromkin (1971), there are a few sporadic mispronunciations that have a similar structure to H-sprung:

- John dropped his cup of coffee $\rightarrow$... cuff of coffee

- also share $\rightarrow$ alsho share

- week long race $\rightarrow$ reek long race etc.

This is superficially similar to phonetic anticipation, but as Fromkin argues, these errors seem to operate on phonological symbols rather than gestures: they happen at a relatively early level of production, sometimes even before the phonological rules of the language have applied.

Garrett and Johnson (2013) propose that a small number of sound changes might start off as motor planning errors of the Fromkin type: specifically, i) consonant harmony systems and ii) long-distance displacement of the type seen in Bagnères-de-Luchon. Hansson (2010) argues for a general analysis of consonant harmony systems as conventionalized speech errors: like speech errors, they tend to involve segments that are already phonetically similar, and the fact that consonant harmony tends to apply right-to-left parallels the tendency of speech errors to be anticipatory more often than perseverative.

In the absence of any more details, an account based on speech errors seems not to explains the facts of the change. For one thing, speech errors are not that common: Fromkin herself only recorded 6oo errors in the database, out of three years of listening for errors in casual speech. With such a low background rate of speech errors, the chances of enough errors accumulating around one lexical item-especially as common a word as a basic pronoun like $\dot{\eta} \mu \varepsilon \hat{\imath} \varsigma-$ 
are intuitively very low. We'd also lose any explanation for the (albeit imperfect) conditioning of the change: there would be no particular reason why all the attested examples in Greek involve $H$-sprung, and not, say, $T$-sprung or $M$ sprung. In general, an account of sound change based on a purely phonological speech errors severs any explanatory link with phonetics.

\subsection{Pre-Grassmann's Law}

Instead of motor planning, we should have an account of $H$-sprung grounded in phonetics. An interesting possibility would be to connect $H$-sprung to another sound change involving spreading of aspiration over a distance: Grassmann's Law. In both Greek and Sanskrit, an aspirated stop (or $h$ ) followed by another aspirate deaspirated (or deleted, respectively), leaving fragmented alternations in inflectional paradigms: $\varphi v \omega^{\omega}$ 'I grow', $\pi \dot{\varepsilon} \varphi v \kappa \alpha$ 'I have grown'.

The modern analysis of dissimilatory sound changes, following Ohala (1981), is that they involve listener hypercorrection for assimilatory coarticulation. Aspirated or breathy-voiced segments have high energy in Fo and high levels of noise (Blevins and Garrett 2004), both of which can last for an extended stretch of the acoustic signal. In the case of Grassmann's Law, the original speaker produces a phonetic output $\left[\mathrm{p}^{\mathrm{h}} \varepsilon \mathrm{p}^{\mathrm{h}}\right]$ faithfully reflecting a surface phonological form $/ \mathrm{p}^{\mathrm{h}} \varepsilon \mathrm{p}^{\mathrm{h}} /$; the listener falsely interprets this form as a coarticulated token of [ $\left.\mathrm{pep}^{\mathrm{h}}\right]$, and so acquires $/ \mathrm{pep}^{\mathrm{h}} /$. Diachronically, this gives us a sound change $/ \mathrm{p}^{\mathrm{h}} \varepsilon \mathrm{p}^{\mathrm{h}} />/ \mathrm{p}^{\mathrm{p}} \mathrm{p}^{\mathrm{h}} /$. But the reasoning of Ohala's story only makes sense if the speaker was expecting assimilation of aspiration: in other words, if Greek at some point contained a (phonetic or phonological) assimilation process that was substantial enough to be worth correcting for. This hypothetical earlier assimilation process would have copied aspiration from an aspirated stop in the middle of a word to an earlier unaspirated stop.

This means we have three processes in the history of Greek-H-sprung, the $\varphi$ poupó rule, and this pre-Grassmann assimilation — with very similar effectsspreading aspiration from the middle of the word to the beginning of a word. Can we treat them as part of the same change?

Table 1 shows an eight-way typology of aspiration effects in Greek, according to the source and target of aspiration in each change. Pre-Grassmann assimilation copied aspiration from a stop to either a stop onset or an empty onset. The $\varphi p o u p \frac{1}{\alpha}$ rule copied aspiration from an ${ }^{*} h$ to a initial stop. $H$-sprung copied aspiration from an ${ }^{*} h$ to an initial empty onset. We can unify these three processes under the umbrella of one single sound change, which I call 'Urhauchumsprung' (or 'Ur-H-sprung'): copy aspiration from the first medial onset, what- 


\begin{tabular}{|c|c|c|}
\hline & Assimilation & Dissimilation \\
\hline$\# \mathrm{~T}_{-} \mathrm{T}^{\mathrm{h}}$ & Pre-Grassmann & Grassmann \\
\hline$\#_{-} \mathrm{T}^{\mathrm{h}}$ & Pre-Grassmann & Grassmann \\
\hline$\# \mathrm{~T}_{-} \mathrm{h}$ & $\varphi p o u p \frac{1}{\alpha}$ & - \\
\hline$\#$ h & $H$-sprung & - \\
\hline
\end{tabular}
1. Loss of intervocalic * $h$
2. Ur-H-sprung
3. Loss of * $h$ in sonorant clusters, causing phonologization of half of $U r-H-$ sprung

4. Grassmann's Law, hypercorrecting for the other half of Ur-H-sprung

ever it is, to the beginning of the word, whatever it is. Because ${ }^{*} h$ and the aspirated stop series as the only segments in Greek that carry aspiration, we can think of this sound change as vacuously applying whenever the target segment is anything else.

In this picture, Grassmann's Law is a hypercorrective effect of $U r$-H-sprung, undoing the stop-conditioned change labelled 'Pre-Grassmann' — and generalizing the context of the change to all cases of an aspirated segment (stop or ${ }^{*} h$ ) followed by an aspirated stop.

But if Grassmann's Law had involved hypercorrection for the other two cases of $U r$ - $H$-sprung, conditioned by medial ${ }^{*} h$, we would expect to see Grassmanntype dissimilation in the context of an aspirated segment followed by ${ }^{*} h$. In fact, one etymology tells us that Grassmann's Law wasn't triggered by intervocalic * $h$ :

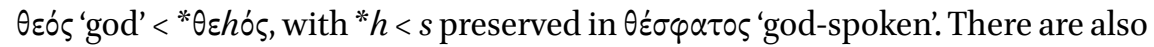
no examples of Grassmann's Law triggered by * $h$ as part of a cluster, and several

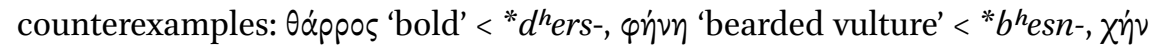
'goose' < ${ }^{*} g^{h} h_{2}$ ens-, and $\chi^{\prime} \lambda$ 1ol 'thousand' < * $g^{h} e s l$-. So why didn't Grassmann's Law also undo $H$-sprung and the $\varphi$ poupó rule?

Table 2 shows a potential explanation in terms of relative chronology. Based on the discussion of the $\varphi p o u p \alpha \bar{\alpha}$ rule in section 2.2, the loss of intervocalic * $h$ must have preceded $U r$-H-sprung. This means $U r$ - $H$-sprung had two triggers: i) medial ${ }^{*} h$-sonorant clusters, and ii) medial aspirated stops. 
Suppose that the loss of $* h$ in sonorant clusters-which must have happened at some point before attested Greek-happened while $U r$ - $H$-sprung was still a synchronic phonetic process. To the first generation of language learners who failed to learn any medial ${ }^{*} h$ s, the ${ }^{*} h$-triggered half of $U r$ - $H$-sprung would have to be phonologized as part of the underlying form of each target word. Without a separate source of aspiration in the word, the learner would be forced to learn $\dot{\eta} \mu \varepsilon \hat{\varsigma}$, ivial, etc. as beginning with genuine $h$.

Once there were no more instances of medial ${ }^{*} h, U r$ - $H$-sprung survived, but now it had a more specific scope: all remaining examples of aspiration effects synchronically derivable from $U r$ - $H$-sprung were triggered by medial stops. Grassmann's Law involved hypercorrection for this later version of $U r$ $H$-sprung, with no hypercorrection for the $h$-triggered cases because those had already been fossilized. If this is true, there's no sleight of hand needed in explaining why Grassmann's Law only undid half of $U r-H$-sprung: in fact, Grassmann's Law undid all cases of Ur-H-sprung that still existed at the time that it applied. This gives us an explanation for the patterns in Table 1.

\section{Conclusion}

The evidence from the ancient Greek lexicon is clear that there was a sporadic sound change that copied an ${ }^{*} h$ from the second syllable of a word to the first syllable, applying when the first syllable was vowel-initial, and perhaps also when it was stop-initial; this complements the analyses proposed so far in Greek historical phonology, particularly Sturm (2016, 2017), in accounting for the various sources of Proto-Greek * $h$. This change, Hauchumsprung, is unusual among recorded sound changes for involving the copying of a consonant over

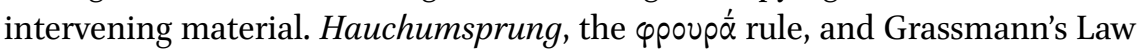
can be unified as three different footprints of a single sound change: one that copied aspiration from the middle of a word to the beginning of a word in early Greek.

\section{References}

Beekes, R.S.P. \& van Beek, L. (2010). Etymological Dictionary of Greek. Leiden: Brill. Blevins, J., \& Garrett, A. (2004). The evolution of metathesis. In Bruce Hayes et al. (eds.), Phonetically Based Phonology, 117-156. Oxford: Oxford University Press.

Brugmann, K. (1908). Griechisch îvos und övos Indogermanische Forschungen 22, 197202. 
Clackson, J. (1994) The Linguistic Relationship between Armenian and Greek. Oxford: Blackwell.

Collinge, N.E. (1985). The Laws of Indo-European. Amsterdam: John Benjamins.

Colvin, S. (2006). Autosegmental phonology and word-internal $-h$ - in Mycenaean Greek. Glotta 82, 36-54.

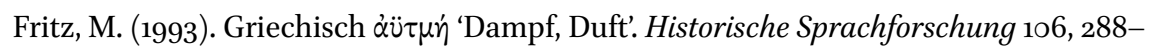
301.

Fromkin, V.A. (1971). The non-anomalous nature of anomalous utterances. Language 47, 27-52.

Garrett, A., \& Johnson, K. (2013). Phonetic bias in sound change. In Alan Yu (ed.), Origins of Sound Change: Approaches to Phonologization, 51-97. Oxford: Oxford University Press.

Grammont, M. (1905). La métathèse dans le parler de Bagnères-de-Luchon. Mémoires de la societé de linguistique de Paris 13, 73-90.

Hall, N., Vasquez, N., Damahuri, M., Aguirre, F., \& Tree, C. (2017). Long-distance liquid coarticulation in American English. In Proceedings of the Annual Meeting on Phonology 2016.

Klingenschmitt, G. (1974) Griechisch parthénos. In Manfred Mayrhofer et al. (eds.), Antiquitatae Indogermanicae. Gedenkschrift für Hermann Güntert, 273-279. Innsbruck: Institut fuer Sprachwissenschaft der Universitaet.

Lejeune, M. (1972) Phonétique historique du mycénien et du grec ancien. Paris: Klincksieck.

Martínez, J., \& de Vaan, M. (2014). Introduction to Avestan. Leiden: Brill.

Martirosyan, H. (2010) Etymological Dictionary of the Armenian Inherited Lexicon. Leiden: Brill.

Meister, R. (1893) Die Mimiamben des Herodas. Leipzig: S. Hirzel.

McCarthy, John J. (1984). Speech disguise and phonological representation in Amharic. In Harry van der Hulst and Norval Smith (eds.), Advances in Nonlinear Phonology, 305-312. Dordrecht: Foris.

Ohala, J.J. (1981). The listener as a source of sound change. In: C.S. Masek et al. (eds.), Papers from the Parasession on Language and Behavior, 178-203. Chicago: Chicago Linguistic Society.

Rankin, R.L., R.T. Carter, A. Wesley Jones, J.E. Koontz, D.S. Rood \& I. Hartmann (eds.) (2006). Comparative Siouan Dictionary. Leipzig: Max Planck Institute for Evolutionary Anthropology.

Ringe, D. (forthc.) The Roots of Greek. Manuscript.

Ruijgh, C.J. (1967). Études sur la grammaire et le vocabulaire du grec mycénien. Amsterdam: A. M. Hakkert.

Ruijgh, C.J. (1970). Review of: P. Chantraine, Dictionnaire étymologique de la langue grecque. Histoire des mots. T. 1. Paris: Klincksieck, 1968. Lingua 25, 302-321. 
Sihler, A. (1995). New Comparative Grammar of Latin and Greek. New York: Oxford University Press.

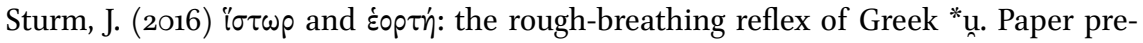
sented at the 28th Annual UCLA Indo-European Conference.

Sturm, J. (2017). Prothetic /h/ before word-initial / $\mathrm{u} /$ in Attic: a word-initial constraint. Paper presented at the 29th Annual UCLA Indo-European Conference. 